\title{
Time to 're-think' physical activity promotion for young people? Results from a repeated cross-sectional study
}

\author{
Paul Best ${ }^{1,2,3^{*}}$ (D) Mark A. Tully ${ }^{2,3}$, Rekesh Corepal ${ }^{2,3}$, Frank Kee $^{2,3}$ and Ruth F. Hunter ${ }^{2,3}$
}

\begin{abstract}
Background: The aim of this study was to investigate the relationship between knowledge of the current UK physical activity (PA) guidelines and amount of daily PA using a sample population of 11-16 year olds in Northern Ireland.

Methods: Cross-sectional survey data from the 2010 and 2013 Young Persons' Behaviour and Attitudes Survey of 10,790 young people provided information on PA, knowledge of guidelines and socio-demographic characteristics. Multinomial logistic regression was used to investigate the associations between knowledge and amount of daily PA.

Results: Results from 2013 showed $67.0 \%$ of respondents were aware of PA guidelines with 15.4\% reporting meeting them. Males were more likely to meet PA guidelines than females (OR 3.36, 95\% Cl 2.47, 4.59). Males who were active for 60 min or more, 7 days per week were less likely to be aware of guidelines ( $O R=1.51,95 \% \mathrm{Cl} 1.02$, 2.24). For females, knowledge of PA guidelines had no significant association with amount of daily PA ( $\mathrm{OR}=1.74,95 \% \mathrm{Cl} 0.99,3.07)$. Those who did not enjoy being active were less likely to meet the guidelines $(\mathrm{OR}=0.05,95 \% \mathrm{Cl} 0.02,0.12)$.

Conclusions: Knowledge did not appear to be an important predictor of PA in young people. Consequently, threshold based messaging containing recommended minimum PA guideline information may not be appropriate for this age group. Re-branding PA promotion to include the use of humour may offer a new direction for public health messaging based around fun and enjoyment.
\end{abstract}

Keywords: UK physical activity guidelines, Knowledge, Health education, Health communication, Young people

\section{Background}

Physical inactivity is the fourth leading cause of mortality in adults, attributable to an estimated 3.2 million deaths worldwide each year $[1,2]$. This problem has its origins early in the life course with research demonstrating that the average time spent in physical activity (PA) falls by $60-70 \%$ from childhood to adolescence $[3,4]$. Physical activity behaviours and habits formed during this time track into adulthood - emphasising the importance of regular PA from a young age [4-6]. The World Health Organisation, recommends children and adolescents should undertake at least $60 \mathrm{~min}$ of moderate to vigorous intensity PA each day [7]. Based on self-report data, (in which respondents typically overestimate PA)

\footnotetext{
* Correspondence: p.best@qub.ac.uk

${ }^{1}$ School of Social Sciences, Education and Social Work, Queen's University Belfast, Belfast, UKBT7 1NN

${ }^{2}$ Centre for Public Health, Queen's University Belfast, Belfast, UKBT7 1NN Full list of author information is available at the end of the article
}

one review suggested that only $30-40 \%$ of young people $(<18$ years old $)$ are sufficiently active to meet these guidelines [8]. The most rapid period of decline occurs during middle adolescence $[4,9]$ and as such more attention is being placed upon increasing PA within this age group.

Mass public health communication campaigns are commonly used by Government and public health organisations to increase public knowledge of how much PA is required for health benefits. This is done in order to improve attitudes and intentions, which may lead to better informed choices and subsequent changes in PA behaviour [10]. These approaches are seen to be more cost effective and provide greater reach than individually focused, practitioner led interventions and can be seen in numerous PA campaigns, such as VERB (U.S), Live long Kids (Canada) Change4Life' (UK), Push Play (New Zealand) 'Get a Life, Get Active' and 'It all adds up' (Northern Ireland) [11-15]. The effectiveness of PA 
interventions using mass marketing campaigns to increase knowledge and change PA behaviour has shown some promise within both child and adult populations $[12,16,17]$. Their popularity is spurred by studies showing poor levels of knowledge of PA guidelines among young people and their parents as a possible associated factor for low PA $[18,19]$.

Informed by core psychological constructs (i.e. knowledge, attitudes and intention) implicit within a number of common behaviour change models e.g. Hierarchy of Effects, Theory of Planned Behaviour etc. [20-23] this type of public health intervention hypothesizes that knowledge can influence attitude, thus leading to changes in behaviour [20, 22] Therefore increasing public knowledge of health behaviours through mass media campaigns is viewed as an attractive population based intervention. However, this 'one size fits all approach' is often criticised in favour of more targeted approaches aimed at higher risk sub-populations [24, 25]. Furthermore, many of these campaigns rely heavily upon threshold messages as a means of encouraging behaviour change e.g. "10,000 steps Ghent" [26]. Threshold messages are designed to "implore individuals to attain a specified volume of behaviour" [27] (p. 195) and are often centred upon a particular set of recommendations. While these messages provide a benchmark in which to measure progress, the extent to which they encourage behaviour change is unclear [28]. Brawley and Latimer (2007, p. 171) note that "guidelines tell people what to do, but not why or how they should do it" [24]. Moreover, the majority of theoretical and empirical evidence has been accumulated from adult populations [28]. Little consideration has been given to the applicably of this approach to affect change in younger populations. This is particularly important given the innate physiological and psychological differences across the life course, such as rational thinking, decision making and future orientation [29].

Current research in adult populations [25, 30] has drawn heavily upon evidence and theory to explain the importance of knowledge of PA guidelines as a means of influencing PA behaviour. Therefore, this study investigates the relationship between knowledge of the current UK PA guidelines and the likelihood of meeting them using a sample population of 11-16 year olds in Northern Ireland. Representative cross-sectional data from two distinct time points enabled identification of common correlates of PA behaviour. This has the potential to inform future public health campaigns and how they might be targeted and tailored for young people.

\section{Methods}

Data were collected from the 2010 and 2013 waves of the Young Persons' Behaviour and Attitudes Survey (YPBAS) [31], a large school based repeated cross-sectional survey of young people aged 11-16 in Northern Ireland (NI) carried out by the NI Statistics and Research Agency (NISRA).

A stratified random sampling procedure, based on census data [32], was used to generate a representative sample based on school size, educational status, management group (i.e. Controlled, Voluntary etc.) and Education and Library Board area (geographical location) across the 175 schools. Data were collected from 77 schools $(n=7616$ respondents) in 2010 and 75 schools ( $n=7076$ respondents) in 2013. Note that YPBAS contained two separate questionnaires (version $\mathrm{A}$ and version B) with pupil's completing version A or B only. In 2010, both versions included demographic information as well as information on physical activity and other health behaviours. However in 2013 the physical activity items were moved to version B only. As such, relevant data was only available for 3174 respondents in 2013. One class was randomly sampled within each year group across Years 8-12 (aged 11-16) using both selfcompleted paper based questionnaires (2010) and online questionnaires (2013). In 2010, the response rate across both versions was $88-90 \%$ whereas in 2013 it was 85-86\%.

Using data from two distinct points increases the reliability and validity of results. The repeated crosssectional design also enables one to follow group changes over time. These surveys are representative of school size, educational status and geographical locale in NI. Further to this, using two time points enabled the research team to investigate the possible impact of the well-publicised UK Chief Medical Officers' Report on PA in 2011 [33].

\section{Dependent variable \\ Physical activity behaviour}

Self-reported PA behaviour was measured using the question "over last 7 days, on how many days have you played any sport, done any physical activity, or played actively that made you out of breath or hot and sweaty for a total of at least $60 \mathrm{~min}$ each day?". This single item question was thought to be appropriate for this age group given the differing age ranges involved and mixed ability of participants. Single item assessments of PA have been shown to be an appropriate measure within previous studies with children [34] albeit with different populations. Furthermore, in other PA studies, single item-measures have shown utility when sample sizes are sufficiently large or that additional measures would add to respondent burden [35]. Responses were categorised as: (1) Active 7 days per week for $60 \mathrm{~min}$; (2) Active 5-6 days per week for 60 min (5-6 (3) Active 2-4 days per week for $60 \mathrm{~min}$; (4) Inactive (1 day or less per week). These categories were chosen in recognition of the fact that 
those who did some but not enough PA, could be very different from those that do no activity at all.

\section{Predictor variables \\ Knowledge of PA guidelines}

Participants were asked "How many minutes do you think you SHOULD spend each day playing sport, doing physical activity or playing actively to make you out of breath or hot or sweaty in order to be healthy?" Responses included $15 \mathrm{~min}, 30 \mathrm{~min}, 60 \mathrm{~min}, 90 \mathrm{~min}$, more than 90 min or 'don't know'. Individuals were categorised into two groups; (1) 'Aware' (i.e. $60 \mathrm{~min}$ ) and (2) 'Unaware'.

\section{Socio-demographic factors}

Data were collected for gender, age, education status, socio-economic position (SEP) and long standing illness. Age was categorised into three groups "11-12 years old", "13-14 years old" and "15-16 years old". Education status was categorised as "secondary" (suggestive of lower to mixed ability) or "grammar" (suggestive of higher ability). Individual SEP was based on provision of free school meals e.g. "Is the pupil entitled to free school meals" (Yes/No). Geographical area based SEP was derived from the Northern Ireland Multiple Deprivation Measure (MDM) [36]. The MDM calculates deprivation using seven different domains (e.g. income, employment, health, education, proximity to services, living environment and crime \& disorder) within pre-defined geographical areas across NI. Respondents are divided into quintiles ranging from the most deprived to the least deprived area of residence. Long standing illness was established by the item "Do you have any physical or mental health conditions or illnesses, lasting or expected to last, for 12 months or more?" (Yes/No).

\section{Other health related factors}

In addition to knowledge of PA guidelines, other variables showing an association with PA were considered based on previous literature [37]. These included enjoyment of sport ("Do you enjoy sport or physical activity"), knowledge of other health guidelines ("How many portions of fruit/vegetables do you think you SHOULD eat each day?"), fruit and vegetable intake ("How many portions of fruit/vegetables do you usually eat each day?"). Enjoyment of sport was categorised as "Yes, a lot", "Yes, a little" and "No, not at all". Knowledge of other health guidelines was established by asking respondents about their knowledge of recommended daily fruit and vegetable intake. Individuals were then categorised into two groups; (1) Aware and (2) Unaware. The final item was self-reported fruit and veg intake which was categorised as "none/little" ( $0-1$ portion per day), "some" (2-4 portions per day) and "sufficient" (5 or more portions per day).

\section{Statistical analyses}

Descriptive statistics were calculated using frequencies and percentages for categorical variables, and weighted to reflect age (year group) and gender across NI. Variables were initially included if they had an association at the $p<0.10$ level. A series of multinomial logistic regression analyses were conducted on both the 2010 and 2013 datasets. Variables were subsequently removed if there were no significant univariate correlation $(p<0.05)$. Self-reported PA behaviour was the dependent variable with those who reported being active for 1 day or less per week (i.e. "Inactive") assigned as the reference category This approach was chosen as the proportional odds assumption was not met within an ordinal regression model $(p=0.01)$. Separate analyses were also conducted with male and female only samples. Data were analysed using the Statistical Package for Science (SPSS) version 22.0 Software for Windows (SPSS Inc, Chicago, USA).

\section{Results \\ Demographic characteristics}

Table 1 shows the demographic characteristics of the 2010 and 2013 YPBAS populations. NI census data shows that $51 \%$ of the population are female with $49 \%$ male. YPBAS (2010) had a 51\% male and $49 \%$ female spread whereas YPBAS (2013) had 56\% male and 44\% female spread. In order to reflect the composition of the Northern Ireland post-primary population, weights were applied to the data to compensate for nonresponse bias in the achieved YPBAS sample. Figures from the 2013/ 14 School Census were used to derive weights. Key demographic characteristics, namely age, gender, education status, and SEP (area and individual level), were similar for 2010 and 2013 samples, and representative of the NI population.

\section{Reported daily PA and knowledge of PA guidelines}

From $2010(n=785)$ to $2013(n=462)$, there was a marginal increase in self-report participation in at least 60 min PA per day from 12.0 to $15.4 \%$. The number of respondents who correctly identified the current minimum PA guidance (i.e. knowledge of PA guidelines) also marginally increased from $66.5 \%(n=1360)$ in 2010 to $67.0 \%(n=1215)$ in 2013.

\section{Correlates of PA behaviour}

Tables 2 and 3 show the results of the multinomial logistic regression investigating correlates of PA behaviour among young people in 2010 and 2013. 
Table 1 Demographic Characteristics of 2010 \& 2013 YPBAS Cohorts

\begin{tabular}{|c|c|c|}
\hline Characteristics & 2010 N (\%) & 2013 N (\%) \\
\hline \multicolumn{3}{|l|}{ Daily PA } \\
\hline Active 7 days per week for 60 mins; & $788(12.0 \%)$ & $462(15.4 \%)$ \\
\hline Active 5-6 days per week for 60 mins & $2335(35.7 \%)$ & $648(21.6 \%)$ \\
\hline Active 2-4 days per week for 60 mins; & $2419(37.0 \%)$ & $1395(46.4 \%)$ \\
\hline Inactive 1 day or less per week & $1002(15.3 \%)$ & $499(16.6 \%)$ \\
\hline \multicolumn{3}{|l|}{ Knowledge of PA Guidelines } \\
\hline Unaware & $2454(32.6 \%)$ & $1039(33.0 \%)$ \\
\hline Aware & $5063(66.5 \%)$ & $2114(67.0 \%)$ \\
\hline \multicolumn{3}{|l|}{ Gender } \\
\hline Male & $3879(51.0 \%)$ & $1613(50.9 \%)$ \\
\hline Female & $3734(49.0 \%)$ & $1554(49.1 \%)$ \\
\hline \multicolumn{3}{|l|}{ Age } \\
\hline $11-12$ years old & $1755(23.1 \%)$ & $658(20.7 \%)$ \\
\hline 13-14 years old & $3053(40.3 \%)$ & $1245(39.2 \%)$ \\
\hline $15-16$ years old & $2773(36.6 \%)$ & $1271(40.1 \%)$ \\
\hline \multicolumn{3}{|l|}{ Education Status } \\
\hline Grammar & $2956(38.8 \%)$ & $1125(36.0 \%)$ \\
\hline Secondary & $4660(61.2 \%)$ & $1998(64.0 \%)$ \\
\hline \multicolumn{3}{|l|}{ Proportion Free School Meal } \\
\hline Yes & $1390(18.3 \%)$ & $546(18.5 \%)$ \\
\hline No & $6209(81.7 \%)$ & $2413(81.5 \%)$ \\
\hline \multicolumn{3}{|l|}{ MDM (Quintile) } \\
\hline 1 (most deprived) & $1470(19.8 \%)$ & $488(16.4 \%)$ \\
\hline 2 & $1604(21.6 \%)$ & $587(19.8 \%)$ \\
\hline 3 & $1621(21.8 \%)$ & $818(27.6 \%)$ \\
\hline 4 & $1429(19.3 \%)$ & $558(18.8 \%)$ \\
\hline 5 (least deprived) & $1299(17.5 \%)$ & $518(17.4 \%)$ \\
\hline \multicolumn{3}{|l|}{ Long term illness } \\
\hline Yes & $840(11.2 \%)$ & $405(12.9 \%)$ \\
\hline No & $6648(88.8 \%)$ & $2722(87.1 \%)$ \\
\hline \multicolumn{3}{|l|}{ Do you enjoy PA } \\
\hline Yes, a lot & $2477(62.7 \%)$ & $2059(65.0 \%)$ \\
\hline Yes, a little & $1036(26.2 \%)$ & $890(28.1 \%)$ \\
\hline No, not at all & $435(11.0 \%)$ & $216(6.8 \%)$ \\
\hline \multicolumn{3}{|l|}{ Daily Fruit and Veg Intake } \\
\hline None/Little (0-1) & $1365(18.3 \%)$ & $159(5.1 \%)$ \\
\hline Some $(2-4)$ & $5110(68.4 \%)$ & $2488(79.4 \%)$ \\
\hline Sufficient (5 or more) & $998(13.4 \%)$ & $487(15.5 \%)$ \\
\hline \multicolumn{3}{|l|}{ Knowledge of Fruit and Veg Guidelines } \\
\hline Unaware & $1974(27.0 \%)$ & $970(31.4 \%)$ \\
\hline Aware & $5348(73.0 \%)$ & $2121(68.6 \%)$ \\
\hline
\end{tabular}

Weights applied to descriptive data above $P A$ physical Activity
In 2010 those achieving the minimum daily PA recommendations (7 days per week for $60 \mathrm{~min}$ ) were more likely $(\mathrm{OR}=1.41,95 \% \mathrm{CI} 1.04,1.93)$ to be unaware of the PA guidelines than those who were inactive. Those who did not meet the guidelines were more likely to be aware of them, for example; active 5-6 days per week $(\mathrm{OR}=0.70,95 \% \mathrm{CI} 0.55,0.89)$ and active 2-4 days per week $(\mathrm{OR}=0.78,95 \%$ CI 0.62, 0.98). In 2013, those achieving the minimum daily PA (7 days) targets were also more likely to be unaware (OR $=1.74,95 \%$ CI 1.29 , 2.35). Those who were active 5-6 days (OR $=0.91,95 \%$ CI $0.68,1.21)$ and those active $2-4$ days $(\mathrm{OR}=1.05,95 \%$ CI $0.79,1.27$ ) were marginally more likely to be aware of minimum PA requirements however these results were not significant $(p>0.05)$.

\section{Other Correlates of PA behaviour}

Daily fruit and vegetable intake also emerged as an significant correlate, with those who reported eating 2 or more portions a day more likely to meet the minimum PA guidelines (2010: OR $=0.25$, 95\% CI 0.16, 0.40; 2013: $\mathrm{OR}=0.24,95 \%$ CI $0.15,0.36$ ). Enjoyment of sport or PA was associated with PA behaviour. Those who did not enjoy being active were less likely to meet the guidelines in both $2010(\mathrm{OR}=0.02,95 \% \mathrm{CI} 0.01,0.07)$ and in 2013 $(\mathrm{OR}=0.05,95 \%$ CI $0.02,0.12)$.

Differences in daily PA and knowledge of PA guidelines in males and females

Gender and age were found to be the two most significant factors related to PA behaviour. Chi-square tests for independence showed that in 2010, females $(69.0 \%, n=$ 1360) were significantly $(\chi 2,75.55, p=0.01)$ more likely to be aware of the PA guidelines than males $(59.9 \%, n=$ 1215). While knowledge of PA guidelines increased slightly in 2013 for both sexes, females $(73.3 \%, n=1132)$ remained more knowledgeable than males $(38.9 \%, n=$ 979) $(\mathrm{x} 2,46.30, p=0.01)$.

This trend however was reversed when examining the participants' reported level of PA. In 2010, 7.2\% $(n=115)$ of female participants reported being active for a minimum of $60 \mathrm{~min}$, seven days per week. Within the same period, $14.0 \%(n=235)$ of male participants reported being active for a minimum of $60 \mathrm{~min}$, seven days per week $\left(\chi^{2}, 22.113, p=0.01\right)$. This gender disparity increased further in 2013 with only $8.0 \%(n=116)$ of females reporting PA in line with the minimum UK guidelines compared with $20.1 \%(n=310)$ of males $(\chi 2,186.22, p=0.01)$.

Separate multinomial regression analyses on male and female sub-groups were performed (see Tables 4 and 5). Males were two to three times more likely to report being active for 7 days per week than females in 2010 $(\mathrm{OR}=2.12,95 \%$ CI 1.54, 2.91) and 2013 (OR 3.36, 95\% 
Table 2 Correlates of daily PA behaviour (2010)

\begin{tabular}{|c|c|c|c|c|}
\hline Predictor Variable & & $\begin{array}{l}\text { Active } 2-4 \text { days per week } \\
\text { OR }[95 \% \text { Cl] }\end{array}$ & $\begin{array}{l}\text { Active } 5-6 \text { days per week } \\
\text { OR }[95 \% \text { Cl] }\end{array}$ & \multirow{2}{*}{$\begin{array}{l}\text { Active } 7 \text { days per week } \\
\text { OR [95\% CI] }\end{array}$} \\
\hline \multirow{4}{*}{ Enjoyment of Sport or PA } & & & & \\
\hline & No, not at all & $0.16[0.15,0.23]$ & $0.06[0.03,0.09]$ & $0.02[0.01,0.07]$ \\
\hline & Yes, a little & $0.48[0.37,0.61]$ & $0.19[0.14,0.25]$ & $0.10[0.06,0.16]$ \\
\hline & Yes, a lot & [Ref.] & - & - \\
\hline \multirow[t]{2}{*}{ Gender } & Male & $0.98[0.78,1.23]$ & $1.52[1.20,1.31]$ & $2.12[1.55,2.91]$ \\
\hline & Female & [Ref.] & - & - \\
\hline \multirow[t]{3}{*}{ Age } & $11-12$ years & $1.26[0.93,1.72]$ & $1.82[1.32,2.52]$ & $4.04[2.66,6.15]$ \\
\hline & $13-14$ years & $1.05[0.83,1.33]$ & $1.53[1.18,1.98]$ & $2.27[1.57,3.28]$ \\
\hline & $15-16$ years & [Ref.] & - & - \\
\hline \multirow[t]{2}{*}{ Knowledge of PA guidelines } & Unaware & $0.78[0.62,0.98]$ & $0.70[0.55,0.89]$ & $1.41[1.04,1.93]$ \\
\hline & Aware & [Ref.] & - & - \\
\hline \multirow[t]{3}{*}{ Daily Fruit and Veg Intake } & None/little (0-1) & $0.52[0.34,0.81]$ & $0.15[0.09,0.24]$ & $0.12[0.07,0.21]$ \\
\hline & Some (2-4) & $1.06[0.71,1.59]$ & $0.45[0.30,0.68]$ & $0.25[0.16,0.40]$ \\
\hline & Sufficient ( 5 or more) & [Ref.] & - & - \\
\hline
\end{tabular}

Reference Category: Somewhat Inactive (0-1 days per week)

$P A$ physical Acitivity

CI 2.47, 4.59). For males, correlates of PA behaviour remained the same in 2010 and 2013, i.e. enjoyment of sport or PA; age; knowledge of PA guidelines; daily fruit and vegetable intake $(p<0.05)$. For females, the correlates of PA behaviour consistent across 2010 and 2013 datasets were enjoyment of sport or PA; age and daily fruit and vegetable intake. Males who were meeting daily PA recommendations were less likely to be aware of the PA guidelines in 2010 or 2013 (OR = 1.51, 95\% CI $1.02,2.24)$. Knowledge of PA guidelines was not a significant correlate with female group in the 2010 or $2013(p>0.05)$.

\section{Discussion}

Results demonstrated that knowledge of the current PA guidelines does not increase the likelihood of meeting them using a sample population of 11-16 year olds in Northern Ireland, confirmed across two different cohorts. Results showed that a high proportion of respondents were aware of the minimum amount of PA needed to maintain a healthy lifestyle. However, contrary to underpinning theoretical models, knowledge did not appear to be associated with the proportion of young people achieving the minimum amount of daily PA. Separate analyses on male and female sub-groups

Table 3 Correlates of daily PA behaviour (2013)

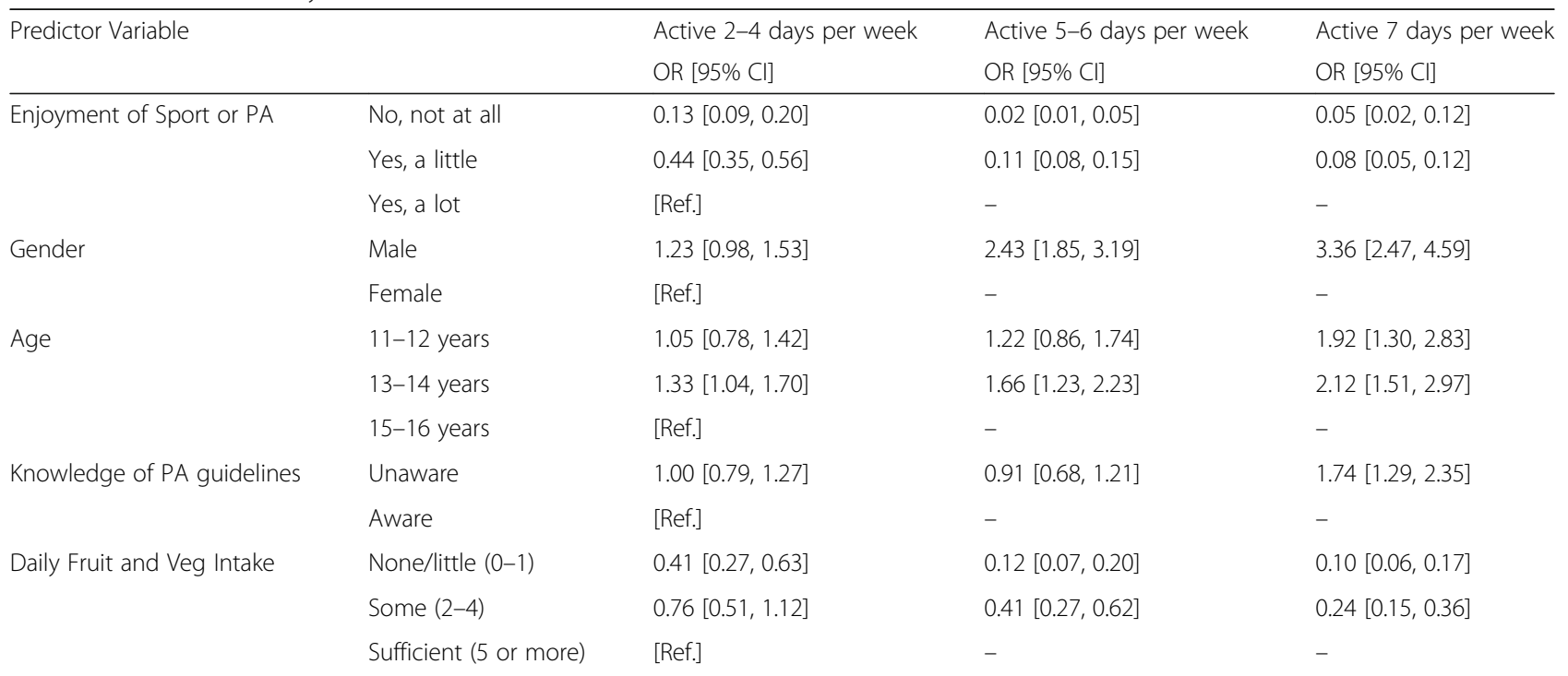


Table 4 Correlates of daily PA behaviour, Females Only (2013)

\begin{tabular}{|c|c|c|c|c|}
\hline Predictor Variable & & $\begin{array}{l}\text { Active } 2-4 \text { days per week } \\
\text { OR [95\% CI] }\end{array}$ & $\begin{array}{l}\text { Active } 5-6 \text { days per week } \\
\text { OR [95\% CI] }\end{array}$ & \multirow{2}{*}{$\begin{array}{l}\text { Active } 7 \text { days per week } \\
\text { OR }[95 \% \mathrm{CI}]\end{array}$} \\
\hline \multirow{4}{*}{ Enjoyment of Sport or PA } & & & & \\
\hline & No, not at all & $0.18[0.11,0.31]$ & $0.01[0.00,0.10]$ & $0.05[0.01,0.22]$ \\
\hline & Yes, a little & $0.54[0.39,0.73]$ & $0.13[0.08,0.21]$ & $0.12[0.06,0.22]$ \\
\hline & Yes, a lot & [Ref.] & - & - \\
\hline \multirow[t]{3}{*}{ Age } & $11-12$ years & $1.19[0.80,1.78]$ & $2.02[1.17,3.50]$ & $2.06[1.05,4.00]$ \\
\hline & $13-14$ years & $1.49[1.07,2.06]$ & $2.16[1.34,3.50]$ & $2.24[1.24,4.07]$ \\
\hline & $15-16$ years & [Ref.] & - & - \\
\hline \multirow[t]{3}{*}{ Daily Fruit and Veg Intake } & None/little (0-1) & $0.38[0.21,0.67]$ & $0.06[0.03,0.15]$ & $0.07[0.03,0.16]$ \\
\hline & Some (2-4) & $0.72[0.43,1.21]$ & $0.31[0.17,0.57]$ & $0.15[0.08,0.29]$ \\
\hline & Sufficient (5 or more) & [Ref.] & - & - \\
\hline
\end{tabular}

Reference Category: Somewhat Inactive (0-1 days per week)

showed that males, in particular, who are meeting current PA guidelines are less likely to know them.

These results appear counter-intuitive given the prominence of various behaviour change theories with which knowledge is a key component. However, other studies of young people's PA have shown a similar disconnect between awareness and compliance which partially supports the findings of this paper [38]. One important area to consider is attitude formation as a segue between increased knowledge and behaviour change. How information contained in public health campaigns is assimilated and assigned importance may depend largely upon how it is communicated, particularly amongst young people. Results reported here suggest campaigns would do well to include approaches and processes through which PA can be viewed as more enjoyable. One study by Martins et al. [39] found that for many adolescents, having 'fun' was a key reason for being active. Physical activity that was over competitive, non-diversified and non-autonomous were seen as barriers. One approach to making PA appear more enjoyable is the use of humour within public health campaigns. This has already gained some momentum with campaigns such as 'Stoptober' and 'the 10 min shake up' $[15,40]$. The 'Laugh Model', is a communication framework which emphasises the importance of humour in health promotion messages as opposed to more threshold based information Lister et al. [41]. This is supported by evidence suggesting that young people were more likely to remember humorous health messages [42]. With this in mind, one must consider if current campaigns are viewed by many young people as representing a 'less enjoyable' side of PA by presenting it within a framework of rules, objectives and guidelines. The 'this girl can' campaign by Sport England is another current example of a mass media campaign that focuses on PA as a social activity which is fun and enjoyable.

While knowledge did not appear to be related to PA, it is important to note that this is not the only factor related to PA behaviour change [3]. More comprehensive

Table 5 Correlates of daily PA behaviour, Males Only (2013)

\begin{tabular}{|c|c|c|c|c|}
\hline \multicolumn{2}{|l|}{ Predictor Variable } & $\begin{array}{l}\text { Active } 2-4 \text { days per week } \\
\text { OR }[95 \% \mathrm{Cl}]\end{array}$ & $\begin{array}{l}\text { Active } 5-6 \text { days per week } \\
\text { OR }[95 \% \mathrm{Cl}]\end{array}$ & $\begin{array}{l}\text { Active } 7 \text { days per week } \\
\text { OR }[95 \% \mathrm{Cl}]\end{array}$ \\
\hline \multirow{4}{*}{ Enjoyment of Sport or PA } & & & & \\
\hline & No, not at all & $0.0 /[0.03,0.14]$ & $0.01[0.00,0.06]$ & $0.04[0.01,0.12]$ \\
\hline & Yes, a little & $0.36[0.25,0.52]$ & $0.09[0.06,0.15]$ & $0.05[0.03,0.10]$ \\
\hline & Yes, a lot & [Ref.] & - & - \\
\hline \multirow[t]{3}{*}{ Age } & $11-12$ years & $1.01[0.64,1.60]$ & $0.94[0.56,1.55]$ & $1.79[1.07,3.02]$ \\
\hline & 13-14 years & $1.14[0.78,1.66]$ & $1.32[0.87,2.00]$ & $1.80[1.15,2.81]$ \\
\hline & $15-16$ years & [Ref.] & - & - \\
\hline \multirow[t]{2}{*}{ Knowledge of PA guidelines } & Unaware & $0.83[0.58,1.17]$ & $0.74[0.50,1.09]$ & $1.51[1.02,2.24]$ \\
\hline & Aware & [Ref.] & - & - \\
\hline \multirow[t]{3}{*}{ Daily Fruit and Veg Intake } & None/little (0-1) & $0.48[0.25,0.89]$ & $0.18[0.09,0.36]$ & $0.14[0.07,0.28]$ \\
\hline & Some (2-4) & $0.87[0.48,1.55]$ & $0.58[0.31,1.05]$ & $0.34[0.19,0.63]$ \\
\hline & Sufficient (5 or more) & [Ref.] & - & - \\
\hline
\end{tabular}


socio-ecological approaches that consider personal, cultural and environmental mechanisms are needed [43]. Campaigns that focus on increasing knowledge are very much targeted at personal level changes without considering that one also needs an environment that supports change. Nonetheless, the underlying assumptions behind many traditional public health campaigns are to focus on increasing knowledge as forerunner to behaviour change. This is also in spite of the fact that much of the evidence base has been garnered from adult populations with little consideration given to the differing cognitive processes through which information is received, processed and acted upon by young people. Furthermore, the theoretical underpinnings of these interventions are not without their critics, particularly when applied to young people. In a discussion of Theory of Planned Behaviour (TPB), Sniehotta and colleagues [44] draw attention to TPB's reliance on 'rational reasoning' a cognitive process which is (arguably) underdeveloped within younger populations. One must therefore consider the validity of some of the core theoretical underpinnings (i.e. knowledge influences intention and behaviour) within these campaigns to affect behaviour change in younger populations. Future public health campaigns may wish to consider alternative theoretical approaches to understanding how best to affect change in younger populations.

In addition to concerns regarding the importance of increasing knowledge of PA guidelines as a behaviour change strategy, there is sometimes a tendency within public health campaigns to adopt a 'one size fits all' approach. In a review of nutritional knowledge and behaviour outcomes, Worsley notes 'lack of relevance' as a key factor, citing that "knowledge of cholesterol may be more relevant to 60 years olds than to 16 years olds - so why teach it to children?" [45]. In terms of PA this might focus more on gender differences e.g. different framing of messages aimed at males and females via social media channels. There is a risk that individuals may find it difficult to relate to information offered about population parameters suggesting that the more effective campaigns are those that target specific groups [46].

Results shown here have implications for future targeted health promotion campaigns aimed specifically at young people by highlighting the importance of enjoyment in relation to PA behaviour.

\section{Strengths and limitations}

This repeated cross-sectional nature of the survey at two time points enabled confirmation of our findings with two large representative population cohorts. However, there are several limitations through which the findings from this study should be interpreted. Due to the crosssectional nature of the surveys, causality cannot be inferred. Moreover, as the study used self-report PA measures it may be subject to reporting or social desirability bias [47]. There is also small possibility that the same respondents may have taken part at both time points due to the sampling strategy employed. This however, is believed to be unlikely as the majority of respondents would have been too old to take part again. Due to the limitation in the dataset we were unable to account for clustering at the school level in our analyses. This study also concentrated mainly on individual level factors. Further research should include social and environmental correlates to further our understanding of multi-level population level factors influencing PA and knowledge.

\section{Conclusion}

Physical activity public health campaigns are at risk of becoming over reliant on threshold based messaging to increase knowledge at the expense of other approaches which may be suited to younger populations. Results have shown that increasing knowledge of PA guidelines was not associated with increased PA behaviour in a large, representative sample of young people. This evidence challenges the current paradigm that suggests that increased knowledge will lead to action. Public health campaigns have the difficult task of providing health information to masses (one size fits all) while targeting specific at risk populations (tailoring). As such, threshold messages have become a simple and direct means in which both to measure and inform the public. Whilst knowledge is an important factor relating to health behaviour change in adults, different approaches may be required to 're-think' and engage younger audiences. As such, the validity of some of the core theoretical underpinnings (i.e. that knowledge strongly influences intention and behaviour) within these campaigns to affect behaviour change in younger populations must be re-considered. The significance of enjoyment of PA in relation to levels of PA point to new directions in public health messaging around humour and fun.

\section{Abbreviations \\ NI: Northern Ireland; NISRA: Northern Ireland statistics and research agency; PA: Physical activity; TPB: Theory of planned behaviour; UK: United Kingdom;} YPBAS: Young persons' behaviour and attitudes survey

\section{Acknowledgements \\ The authors would like to acknowledge support from the UKCRC Centre of Excellence for Public Health (NI).}

\section{Funding \\ Not applicable.}

Availability of data and materials

This data was accessed through a secondary source and is freely available from the UK data archive (https://www.ukdataservice.ac.uk/). 


\section{Authors' contributions}

$\mathrm{PB}$ and $\mathrm{RH}$ were responsible for the analysis of the data. FK, MT and $\mathrm{RC}$ helped to conceptualise the ideas. The article was drafted by PB, RH and RC (introduction) and all authors critically reviewed drafts of the article. PB, $\mathrm{RH}$ MT, FK, and RC were responsible for the interpretation of the findings. All authors approved the final version of the manuscript.

\section{Competing interests}

There authors declare that they have no competing interests.

\section{Consent for publication}

Not applicable.

\section{Ethics approval and consent to participate}

No formal ethics was needed as this was secondary data analysis.

\section{Author details}

'School of Social Sciences, Education and Social Work, Queen's University Belfast, Belfast, UKBT7 1NN. ${ }^{2}$ Centre for Public Health, Queen's University Belfast, Belfast, UKBT7 1NN. ${ }^{3}$ UKCRC Centre of Excellence for Public Health (NI), Queen's University Belfast, Belfast, UKBT7 1NN

\section{Received: 24 September 2016 Accepted: 15 February 2017} Published online: 17 February 2017

\section{References}

1. World Health Organisation. Global health risks: mortality and burden of disease attributable to selected major risks. Geneva: World Health Organisation; 2009.

2. Kohl HW, Craig CL, Lamber EV, Inoue S, Alkandari JR, Leetongin G, Kahlmeier S. The pandemic of physical inactivity: global action for public health. Lancet. 2012;380:294-305.

3. Van Sluijs EMF, McMinn AM, Griffin SJ. Effectiveness of interventions to promote physical activity in children and adolescents: systematic review of controlled trials. Brit Med J. 2007:335:1-13.

4. Dumith SC, Gigante DP, Domingue MR, Kohl HW. Physical activity change during adolescence: a systematic review and a pooled analysis. Int J Epidemiol. 2011;40:685-98.

5. Kriemler S, Meyer U, Martin E, van Sluijs EMF, Andersen LB, Martin BW. Effect of school-based interventions on physical activity and fitness in children and adolescents: a review of reviews and systematic update. Brit J Sports Med. 2011:45:923-30.

6. Rachele JN, Cuddihy TF, Washington TL, et al. The association between adolescent self-reported physical activity and wellness : the missing piece for youth wellness programs. J Adol Health. 2014;55:281-6.

7. World Health Organisation. 'Physical activity and young people', globa strategy on diet, physical activity and health. Geneva: World Health Organisation; 2014.

8. Ekelund U, Tomkinson G, Armstrong N. What proportion of youth are physically active? Measurement issues, levels and recent time trends. Brit J of Sports Med. 2011:45:859-65.

9. Townsend N, Wickramasinghe K, Williams J, Bhatnagar P, Rayner M. Physical activity statistics. London: British Heart Foundation; 2015.

10. Brown DR, Soares J, Epping JM, Lankford TJ, Wallace JS, Hopkins D, Orleans $C T$. Stand-alone mass media campaigns to increase physical activity. Am J Prev Med. 2012;43:551-61.

11. Bauman A, McLean G, Hurdle D, Walker S, Boyd J, Van Aalst I, Carr H Evaluation of the national "push play" campaign in New Zealand - creating population awareness of physical activity. New Zeal Med J. 2003;116:1-11.

12. Huhman M, Potter LD, Wong FL, Banspach SW, Duke JC, Heitzler CD. Effects of a mass media campaign to increase physical activity among children: year-1 results of the VERB campaign. Pediatrics. 2005;116:277-84.

13. Faulkner GEJ, Kwan MYW, MacNeill M, Brownrigg M. The long live kids campaign: awareness of campaign messages. J Health Comun. 201 1;16:519-32.

14. Chalkley A, Milton K, Foster C. Change4Life evidence review: rapid evidence review on the effect of physical activity participation among children aged 5-11 years. London: Public Health England; 2015.

15. Public Health Agency. 'Get a life, get active' [Online]. 2013. Available from: http://www.getalifegetactive.com/. Accessed 15 Oct 2015.
16. Craig CL, Bauman A, Gauvin L, Robertson J, Murumets K. ParticipACTION: A mass media campaign targeting parents of inactive children; knowledge, saliency, and trialing behaviours. Int J of Behav Nut Phys Act. 2009;6:88.

17. Leavy JE, Bull FC, Rosenberg M, Bauman A. Physical activity mass media campaigns and their evaluation: a systematic review of the literature 2003-2010. Health Educ Res. 2011;26:1060-85.

18. DeBastiani SD, Carroll DD, Cunningham M, Lee S, Fulton J. Awareness and knowledge of the youth 2008 physical activity guidelines for Americans. J Phys Act Health. 2014;11:495-501.

19. Marques A, Martins J, Sarmento H, Rocha L, Carreiro da Costa F. Do students know the physical activity recommendations for health promotion? J Phys Act Health. 2015;12:253-6.

20. Lavidge RJ, Steiner GA. A model for predictive measurements of advertising effectiveness. J Marketing. 1961;25:59-62.

21. Prochaska JO, DiClemente CC. Stages and processes of self-change of smoking: toward an integrative model of change. J Consult Clin Psych. 1983:51:390-5

22. Ajzen I. From intention to actions: a theory of planned behavior. In: Kuhl J, Bechmand J, editors. Action control: from cognition to behavior. New York: Springer; 1985.

23. Locke EA, Latham GP. Goal setting theory. In: O'Neil Jr HF, Drillings M, editors. Motivation: theory and research. New York: Lawrence Erlbaum Associates; 1994

24. Brawley LR, Latimer AE. Physical activity guides for Canadians: messaging strategies, realistic expectations for change, and evaluation. Can J Pub Health. 2007:98:170-84.

25. Hunter RF, Tully MA, Donnelly P, Stevenson M, Kee F. Knowledge of UK physical activity guidelines: Implications for better targeted health promotion. Prev Med. 2014:65:33-9.

26. De Cocker KA, De Bourdeaudhuij IM, Brown WJ, Cardon GM. Effects of "10,000 Steps Ghent". Am J Prev Med. 2007:33:455-63.

27. Knox ECL, Webb OJ, Esliger DW, Biddle SJH, Sherar LB. Using threshold messages to promote physical activity: Implications for public perceptions of health effects. Eur J Pub Health. 2014;24:195-9.

28. Knox ECL, Esliger DW, Biddle SJH, Sherar LB. Lack of knowledge of physical activity guidelines: can physical activity promotion campaigns do better ? BMJ Open. 2013:3:1-6.

29. Balbernie R. Circuits and circumstances: the neurobiological consequences of early relationship experiences and how they shape later behaviour. J Child Psych. 2001;27:237-55.

30. Moore LV, Fulton J, Kruger J, McDivitt J. Knowledge of physical activity guidelines among adults in the United States, healthstyles 2003-2005. J Phys Act Health. 2010;7:141-9.

31. Northern Ireland Statistics and Research Agency. Central Survey Unit. (2015). Young Persons' Behaviour and Attitudes Survey, 2013. [data collection]. UK Data Service. SN: 7624, [Accessed 5th July 2016]

32. Northern Ireland Statistics and Research Agency (2016): 2011 Census aggregate data. UK Data Service (Edition: June 2016). http://dx.doi.org/10. 5257/census/aggregate-2011-1.

33. Department of Health. Start active, stay active: a report on physical activity from the four home countries. Chief Medical Officers, London. 2011. https:// www.gov.uk/government/publications/start-active-stay-active-a-report-onphysical-activity-from-the-four-home-countries-chief-medical-officers. Accessed 16 Jan 2017.

34. Scott JJ, Morgan PJ, Plotnikoff RC, Lubans DR. Reliability and validity of a single-item physical activity measure for adolescents. J Paediatr Child Health. 2015:51:787-93. doi:10.1111/jpc.12836.

35. Gill DP, Jones GR, Zou G, Speechley M. Using a single question to assess physical activity in older adults: a reliability and validity study. BMC Med Res Methodol. 2012;12:1-10.

36. Northern Ireland Statistics and Research Agency. Northern Ireland Multiple Deprivation Measure (NIMDM). [Online]. 2005. Available from: http://www. nisra.gov.uk/archive/deprivation/nimdm2005fullreport.pdf www.nisra.gov. uk. Accessed 16 Oct 2016.

37. Sterdt E, Liersch S, Walter U. Correlates of physical activity of children and adolescents: a systematic review of reviews. Health Educ J. 2014;73:72-89.

38. Corder K, van Sluijs EMF, Goodyer I, Ridgway CL, Steele RM, Bamber D, et al. Physical activity awareness of british adolescents. Arch Pediatr Adolesc Med. 2011;165:603-9.

39. Martins J, Marques A, Sarmento H, Carreiro da Costa F. Adolescents' perspectives on the barriers and facilitators of physical activity: a systematic review of qualitative studies. Health Educ Res. 2015;30:742-55. 
40. Public Health England. Change4Life and Disney launch summer 10 Minute Shake Up campaign. Press Release. 2014. Available from https://www.gov. uk/government/news/change4life-and-disney-launch-summer-10-minuteshake-up-campaign. Accessed 23 Oct 2015.

41. Lister C, Royne M, Payne HE, Cannon B, Hanson C, Barnes M. The laugh model: reframing and rebranding public health through social media. Am J Pub Health. 2015;105:2245-51.

42. Gold J, Lim MS, Hellard ME, Hocking JS, Keogh L. What's in a message? Delivering sexual health promotion to young people in Australia via text messaging. BMC Public Health. 2010;10:792.

43. Bauman AE, Reis RS, Sallis JF, Wells JC, Loos RJF, Martin BW. Correlates of physical activity: why are some people physically active and others not? Lancet. 2012;380:258-71.

44. Sniehotta FF, Presseau J, Araújo-Soares V. Time to retire the theory of planned behaviour. Health Psych Rev. 2014;8:1-7.

45. Worsley A. Nutrition knowledge and food consumption: can nutrition knowledge change food behaviour? Asia Pacific J Clin Nutr. 2002;11:S579-85.

46. Olson JM, Zanna MP. Understanding and promoting exercise: a social psychological perspective. Can J Pub Health. 1987;78:S1-7. 1.

47. Adams SA, Matthews CE, Ebbeling CB, Moore CG, Cunningham JE, Fulton J, Hebert JR. The effect of social desirability and social approval on self-reports of physical activity. Am J Epidemiol. 2005;161:389-98.

Submit your next manuscript to BioMed Central and we will help you at every step:

- We accept pre-submission inquiries

- Our selector tool helps you to find the most relevant journal

- We provide round the clock customer support

- Convenient online submission

- Thorough peer review

- Inclusion in PubMed and all major indexing services

- Maximum visibility for your research

Submit your manuscript at www.biomedcentral.com/submit
C Biomed Central 